Archivum, LXIX, 2019, pp. 85-122

\title{
Averamientu al estudiu sociollingüísticu d'un criptolectu gremial: el bron de Miranda
}

\author{
Alba Carballo López \\ UNIVERSIDÁ D'UviÉU \\ albacarballoast@gmail.com
}

Recibido: 27/10/2018

Aceptado: 5/6/2019

\section{RESUMEN:}

Los miembros de determinados grupos de artesanos desarrollaron, históricamente, sistemas lingüísticos secretos conocidos como jergas gremiales. Estas jergas han sido objeto de diversos estudios, pero nunca se les había prestado atención desde el punto de vista de la sociolingüística. Aquí se propone adoptar este enfoque para el estudio de una de las jergas gremiales asturianas: el bron de Miranda (Avilés). Con ello se pretende constatar tanto el nivel de pervivencia, y hasta qué punto determinados elementos lingüísticos se transfieren al habla común, como el conjunto de valoraciones sociales en torno a la jerga.

PALABRAS CLAVE: bron, caldereros, jerga, criptolecto, estudio sociolingüístico, asturiano.

An approach to a sociolinguistic study of a guild cryptolect: bron of Miranda

\section{ABSTRACT:}

The members of certain artisan groups developed, historically, secret linguistic systems known as guild slangs. These jargons have been object of several studies, but they 
have never been addressed from a sociolinguistic point of view. Here we propose to adopt this approach for the study of one of the Asturian guild slang: bron of Miranda (Avilés). The purpose of this study is to verify both the persistence level and to what extent certain linguistic elements are transfered to ordinary speech, such as the set of social worth associated to the jargon.

KEY WORDS: bron, boilermakers, guild slang, cryptolect, sociolinguistic study, Asturian

\section{Les xergues secretes y el bron}

Entiéndese como xerga un llinguax especial que tien una finalidá críptica ${ }^{1}$, polo que tamién se denominen con frecuencia criptolectos. Son llingües creaes con una doble intención: per un llau, l'entendimientu ente los individuos d'un grupu y, per otru, la non comprensión por parte de xente ayeno al mesmu. Hai consensu ente los estudiosos de les xergues pa nomar esti tipu de fales baxo'l nome de xerga o criptolectu gremial y non tanto como un argot propiamente ${ }^{2}$.

Jorge Rodrigues Gomes (2008:17) pon l'atención sobre’1 fechu de qu'una xerga ye "a linguagem especial utilizada por diferentes profissõns para aludir a conceitos, acçõns ou objectos próprios e específicos da sua actividade profissional" y onde añade que ye "utilizada polos membros de diversos grémios tradicionais, na sua maioria artesaõs e/ou ambulantes, com finalidade esotérica".

Estes xergues tienen un valor identitariu fuerte ya que caractericen a estos artesanos como grupu; el bron, concretamente, a los caldereros. Destaca tamién -y esto diferencia los criptolectos gremiales de los argots- l'eleváu gráu d'elaboración: los términos nacen de procedimientos de derivación de palabres, sufixación, metátesis, etc. Anque tamién son comunes la modificación se-

1 El DALLA (Diccionariu de la Llingua Asturiana recueye xerga como "Xíriga, falaxe [especial qu'usen los miembros d'un gremiu, d'un grupu]".

2 Non pa Canellada (1983:131), que defende que, al emplegar estes fales términos de la llingua común tresformaos y que nun nacen d'una especialización léxica de realidaes de la profesión, puen ser catalogaes — fala ella de la xíriga — como un argot. 
mántica y l'usu de préstamos. Empléguense palabres de la llingua base, l'asturianu, y modifíquense. Ye mui raro qu'estes palabres de la xerga pasen a formar parte de la llingua común, dalgo que sí pasa colos argots (como la fala de la mocedá). Precisamente, una de les funciones de les xergues ye la de nun ser entendíes por xente ayeno. Poro, nun suel haber tresvase de términos a la llingua común ${ }^{3}$.

El contestu xeográficu nel que surdíen estes xergues reduzse siempres a una parroquia o una comarca, pero los artesanos teníen una vida ambulante. Esti fechu, según defenden estudiosos como Rodrigues Gomes (2008: 31), contribúi a que se xenerara un prexuiciu, considerándolos negativamente y convirtiéndolos poco a poco nun grupu marxinal. Poro, la fala podía tener un fin catárticu o de lliberación pa colos sos males y los causantes de les miseries que-yos acontecíen. En palabres de Canellada (1983:131), “A fin de cuentas, lo que produce el nacimiento del habla secreta que nos ocupa es la reacción a la presión que un medio hostil ejerce sobre un grupo minoritario".

Nel noroeste de la Península Ibérica concéntrense les xergues gremiales del territorio español y portugués. Podemos clasificales según delles árees (Rodrigues, 2008): nel área portuguesa, nueve criptolectos gremiales; nel área gallega: otros nueve; nel área castellana, cinco y nel área asturlleonesa, otros nueve ${ }^{4}$.

3 Ye perdifícil que los términos emplegaos nestes xergues pasen a ser d'usu común, pero sí hai que señalar, como escepción, los llugares o parroquies onde tienen orixe estes xergues. La xente cercano a los profesionales qu'emplegaben estes fales puen llegar a conocer dalgunu de los términos emplegaos, como veremos nesti estudiu sobre'l bron. De toes formes, fuera d'esta escepción xeográfica, nun ye frecuente qu'un términu d'una xerga gremial pase a formar parte de la llingua común.

4 Rodrígues Gomes (2008:279) presenta un total de siete xergues pal área asturlleonesa en xeneral. Fala del burón como propiu d'El Bierzu, y pal territoriu asturianu reserva un total de seis criptolectos. Nun fala del maconeiru y xune'l bron de Miranda col de San Xuan baxo'l nome xeneral de bron, pero ensin dar un tratu individual. Sí ufren descripciones diferenciaes del bron (estremando ente'l de Miranda y el de San Xuan de Villapañada) otros estudiosos como Ramón d'Andrés (2008:420) 
D'estes últimes, ocho pertenecen al dominiu asturianu, y la novena caería de la parte d'El Bierzu. N'Asturies los criptolectos gremiales fueron oxetu d'estudios diversos ${ }^{5}$-a escepción del maconeiru (Álvarez, 2006:108)—, pero ensin llegar a ser del estilu de les monografíes dialectales del Principáu. Estes son: el texileiru o cunqueiro (que se conoz tamién como tixileiru), el mansolea ${ }^{6}$, el varbéu, la xíriga, l'ergue, el maconeiru, el bron de San Xuan y el bron de Miranda. Dientro del Bierzu -dominiu asturleonésalcontraríemos el Burón. El repartu xeográficu sedría: el tixileiru ye la xerga propia de los cunqueiros d'Ibias; el bron, la de los caldereros de Miranda (parroquia d'Avilés); l'ergue ${ }^{8}$, la de los canteros de la zona oriental (Llanes y Ribesella especialmente); la xíriga o tamargu, tamién de los canteros del oriente; el varbéu, de los cesteros de Peñamellera; el mansolea, de los zapateros de Pimiangu, y el maconeiru, de los cesteiros de Degaña. Dalgunes tán íntimamente relacionaes o son complementu d'una mayor. Pue ser esti el motivu pol que'l maconeiru nun se contempla de forma separada en munchos estudios. D'esta forma, el bron de San Xuan ye complementu del bron de Miranda, l'ergue yelo de la xíriga, y el maconeiru yelo del tixileiru (Andrés, 2008:421). Amás, correspuenden toes a grupos que desempeñaben los sos llabores de venta de forma ambulante.

5 García Arias (2004:139) fai una nómina de tolos autores que, hasta la fecha, dedicaron unes páxines a los estudios d'estes xergues. Asina, cita a: Aurelio de Llano, Joseph A. Fernández, José Manuel Feito, F. García, Max Leopold Wagner, Elviro Martínez, María Josefa Canellada y Emilio Muñoz Valle.

6 Conosze popularmente tamién como jerigonza (otros nomes pa esta xerga son: el chicoria, el mascuence y la jerigoncia) (Campandegui, 2004:174).

7 Rodrigues Gomes, op.cit., nun inclúi'l maconeiru nel so estudiu; tampoco Xuan Xosé Sánchez Vicente (2004) inclúi un artículu sobre esti en Xírigues. Lengua y vida de los artesanos asturianos ambulantes.

8 En delles ocasiones estrémase ente ergue y la xíriga de los tamargos o tamargu, pero Celina Pérez Melero (2004:94) defende que, nel momentu, constituyeron un mesmu argot. 
El bron ye la xerga qu'emplegaben los caldereros de Miranda hasta mediaos del sieglu xx y dende'l sieglu xvirI. La relación del cobre con la zona de Miranda ye una clave históri$\mathrm{ca}^{9}$. L'orixe de los caldereros ye oxetu de numberoses lleendes y hipótesis (Feito, 2002:17). La calderería foi una pieza clave de la economía mirandina, pero de la qu'entamaba llegar la industrialización a la villa d'Avilés l'artesanía d'estos trabayadores foi morriendo hasta desapaecer. D'esti mou, desapaez tamién el bron; al morrer l'oficiu, nun hai necesidá social d'una xerga. El bron esiste tamién fuera de Miranda: en San Xuan de Villapañada ${ }^{10}$ (Grau), la relación d'esti pueblu colos caldereros vendría dada pol fechu de que la ruta interior de comerciu facíase siguiendo'l Caminu Primitivu de Santiago (Valdés, 2008:36).

El primeru en facer una recopilación del léxicu d'esta xerga foi Mariano Cubí i Soler, hacia 1846 (Feito, 2005:29) nun manuscritu del que da fe Ricardo Carvalho Calero tituláu Um manuscrito de dom Mariano Cubí y Soler. Depués hai que destacar los estudios de Julio Ballesteros en 1919 y la recopilación de vocabulariu d'Aurelio de Llano 1921. Más allá de les recopilaciones de léxicu, tamién Fermín Canella Secades (1886:255) fizo referencia a los caldereros de Miranda, n'Avilés, como artesanos que davezu salíen del llugar onde vivíen, como otros munchos artesanos asturianos, y fai tamién una referencia al bron. Nos últimos decenios, cabría destacar el llabor de recopilación de José Manuel Feito, pero nun planu de mayor procuru y fondura nos aspectos llingüísticos, la obra de Rodrigues Gomes supón un puntu culminante. En términos xe-

9 Munches veces, la etimoloxía de bron atribúise a qu'estos artesanos trabayaben el bron-ce (Feito, 1977:78), pero tamién hai delles referencies a que, nel mesmu bron, la voz significa 'engañu', 'mentira'. Hai en xeneral diversidá de teoríes al rodiu del orixe del nome de la xerga, ensin llegar a un consensu.

10 Villapañada sería'l términu modernu que sustituyó a Leñapañada (Valdés, 2008:13). 
nerales, la reconstrucción y recopilación d'elementos del bron ye güei mui satisfactoria ${ }^{11}$.

Tomando como referencia los estudios esistentes sobre esta xerga, y adoptando un puntu de vista sociollingüísticu ${ }^{12}$, presento una panorámica xeneral de la pervivencia del bron al empar qu'una diferenciación ente'l bron tradicional y les manifestaciones más actuales, que voi denominar equí neobrón ${ }^{13}$. Interesa tamién constatar la valoración social que se fai d'esta xerga. Búscase, asina, la esistencia d'un estigma llingüísticu (históricu o actual) pa col bron y los brongarliantes ${ }^{14}$.

Esta xerga, como les otres, tiende a la estabilidá. Equí entra'1 conceptu de rede social propiu de la teoría homónima qu'estudia la estructura social como un conxuntu de vínculos que xunen a un conxuntu d'actores. Rede social defínese como "el tejido formado por las relaciones entre un conjunto de actores que están unidos directa o indirectamente mediante compromisos, informaciones, etc" (Requena, 1998: 635).

11 Nun ye asina pa otres xergues, de reconstrucción más difícil o imposible, como l'ergue de los canteros de la zona oriental d'Asturies que se considera "hoy prácticamente imposible de reconstruir" (García, 1975:388).

12 Tradicionalmente, la sociollingüística ye la disciplina que se vien encargando del estudiu de les llingües dientro d'un contestu social determináu, tanto diacrónica como sincrónicamente. La novedá principal d'esti estudiu ye'l fechu de qu'esta dimensión d'análisis sociollingüísticu nun se fai pa una llingua natural, sinón pa una xerga gremial.

13 Acuño'l términu neobrón nesti trabayu pa referime a dalgunes espresiones o términos que nun pertenecíen al repertorio léxicu tradicional del bron qu'emplegaben los caldereros sincrónicamente, sinón que son frutu d'una recoyida mui posterior o, mesmamente, de la creación de los estudiantes o interesaos actuales del bron. Nel diccionariu de Feito (2002) señala, precedíos pol signu \#, los términos que se crearon nos cursos de bron ente 1996 y 2002.

14 Términu popular actualmente que ta formáu a partir de bron como nome de la xerga y garliante como 'falante', al ser garliar el verbu tradicional del bron pa 'falar'. 
Pue suponese la esistencia d'una rede social fuerte nel contestu históricu nel que los caldereros emplegaben el bron. Nun paez difícil llegar a conclusión tala si se sigue la metodoloxía aportada polos estudiosos, que parte de cinco indicadores de multiplicidá y densidá (L. Morales, 2004: 119). Los caldereros cumpliríen al máximu l'indicador de vecindá —como la participación nun grupu—, el parentescu —al reducise a un espaciu xeográficu tan pequeñu-, el compañerismu llaboral — toos yeren artesanos ambulantes y compartíen oficiu—, el compañerismu laboral y mesmu sexu, y l'amistá - munches veces, pol calter ambulante del oficiu, teníen que mantener relación más allá de lo estrictamente llaboral. Paez claro que seríen exemplu d'una rede social fuerte y que, por ello, el grau de conformismu llingüísti$\mathrm{cu}$ ye mayor, al empar que la so forma de falar taría condicionada polos criterios del propiu grupu y preferencia por formes de menos prestixu social. De toes formes, esta suposición d'una rede social fuerte nun va más allá de sofitar la escasa variación llingüística que pue topase. L'emplegu metodolóxicu del modelu de les redes sociales tien una utilidá mui pequeña dientro de los estudios sociolingüísticos ${ }^{15}$ (Requena, 2002: 10).

Sí paez importante destacar, siguiendo la propuesta de Moreno Fernández ${ }^{16}$, qu'un grupu gremial como los caldereros formaríen parte d'una unidá primaria de producción, como encargaos de guarnecer ${ }^{17}$ les calderes. Ello supón la cooperación de los compañeros, la implicación de la familia, l'autoempléu y, por tanto, la conformación d'una rede social densa.

15 Por ser efectivu casi esclusivamente a la sociedá d'Estaos Xuníos de mediaos del xx onde se fizo l'estudiu del que naciól conceptu.

16 A través de Lopez Morales (2004:121).

17 Con guarnecer defínese en bron el llabor concretu que teníen los caldereros, que nun yera tanto fabricar calderes como rematales. 


\section{Metodoloxía y encuestación}

Pa esti estudiu trabayóse con una muestra del 2\% de la población de Miranda ${ }^{18}$, col repartu siguiente:

a) Un terciu de menores de 35 años: 5 muyeres y 5 homes, toos con estudios universitarios y/o secundarios, y non venientes de familia de caldereros ${ }^{19}$. (Nacíos n'Avilés, y con residencia en Miranda de va más de cinco años)

b) Un terciu d'adultos d'ente 35 y 65 años: 5 muyeres y 5 homes, con estudios equivalentes a Secundaria los homes y el $60 \%$ de les muyeres, y estudios primarios les muyeres restantes. Como familia de caldereros, únicamente un $20 \%$ de los homes, y un $20 \%$ de les muyeres. (Nacíos en Miranda y residencia siempres na mesma parroquia)

c) Un terciu d'adultos mayores de 65 años: 5 muyeres y 5 homes, con estudios primarios el $80 \%$ de los homes y universitarios el $20 \%$ d'ellos, y estudios primarios el $100 \%$ de les muyeres. Como familia de caldereros, el $60 \%$ de los homes, y el 60\% de les muyeres. (Nacíos en Miranda y residencia siempres na mesma parroquia).

Los puntos d'encuestación son un total de 14 de llugares, a saber: L'Alfaraz, Cruz d'Illes, La Lleda, El Pozo la Granda, Bidoleo, Bao, La Cruz de la Foguera, Miranda, Santana, Villanueva, Los Calvos, Heros, L'Anduvisa y Santo Domingo (Feito, 2014:52).

18 La parroquia de Miranda tien una población d'unos 1500 habitantes. Por ello, los encuestaos equí suponen una representación d'un 2,00\% de la población mirandina (30 informantes).

19 La nómina de caldereros de Miranda pue consultase, como fonte primaria, nes Relaciones del Ramo Real de La Riera de Miranda, nº 6, Avilés, Estadística de 1771, pero tamién na obra de Feito (2004:56 y 2002:39). 


\section{Resultaos}

\subsection{Datos que tien la xente acerca del bron}

Los encuestaos destaquen que la característica más sobresaliente del bron ye'l calter crípticu o secretu. Más de trés cuartes partes $(76,7 \%)$ señalen que s'emplegaba pa nun ser entendíos. Tiende tamién a destacase que'l bron yera una marca de grupu, seña d'identidá nel so momentu.

En cuanto al orixe de les palabres del bron, paez poder constatase qu'en nengún de los grupos hai unes conocencies mui definíes, pero sí pue apreciase cómo, a menor edá de los encuestaos, el desconocimientu aumenta. Nos menores de trenta y cinco años les rempuestes señalen llingües fonte un tanto arbitraries: llingües africanes, báltiques, asiátiques..., quiciabes simplemente por señalar llingües d'intelixibilidá más difícil dende'l puntu de vista del castellanu o l'asturianu. Les más recurrentes nes rempuestes de los trés grupos d'edá y sexu son: asturianu ${ }^{20}$ (más de la metá de los encuestaos), vascu ${ }^{21}$ (más de la metá de los encuestaos), portugués, gallegu, francés ${ }^{22}$ y castellanu. Al empar, del total d'encuestaos de los grupos H 35-65, M 35-65 y H>65 y M>65, un 25\% señalen la esistencia procedimientos de deformación de palabres

20 De los encuestaos, un 56,6\% identifiquen munchos términos del bron col asturianu y un $60 \%$ col gallegu. Un porcentax bastante ampliu destaca les relaciones del bron cola llingua asturiana, especialmente detectáu nos grupos H 35-65, M 35-65 y $\mathrm{H}>65$ y $M>65$, onde la respuesta del asturianu se rexistra nun $65 \%$. La cuestión de la semeyanza del asturianu col bron foi oxetu de debate yá en tiempos anteriores. D'esti mou Aurelio de Llano (1921) considera que bron y asturianu (bable como él lo refier) nun poseen semeyanza. Pela contra, Cubí i Soler sí defiende un grau de parentescu eleváu ente la xerga y la llingua asturiana, asina como la gallega (Feito, 2005:42). Ramón d'Andrés (2013:22) defiende que les ocho xergues asturianes tomen como llingua base l'asturianu nes sos distintes variedaes xeográfiques.

21 Nun ye difícil topar elementos vascos nel léxicu del bron de Miranda (Andrés, 2008: 422), y paez que ye daqué conocío polos informantes.

22 Únicamente rexistráu nos grupos d'edá H>65 y M>65 nun 30\%, falando de la rexón francesa d'Auvernia y de la posible incorporación de términos franceses como moi, toi o fromaxe. 
per aciu de sufixos o alteración fónica; d'ellos, un $60 \%$ son familia de caldereros y el $40 \%$ restante acudió a cursos de bron.

No que se refier a les situaciones onde s'usaba'l bron, la opinión mayoritaria diz que s'emplegaba pa falar con otros compañeros caldereros, especialmente en ruta comercial o cuando nun queríen ser entendíos falar (ver Fig.1):

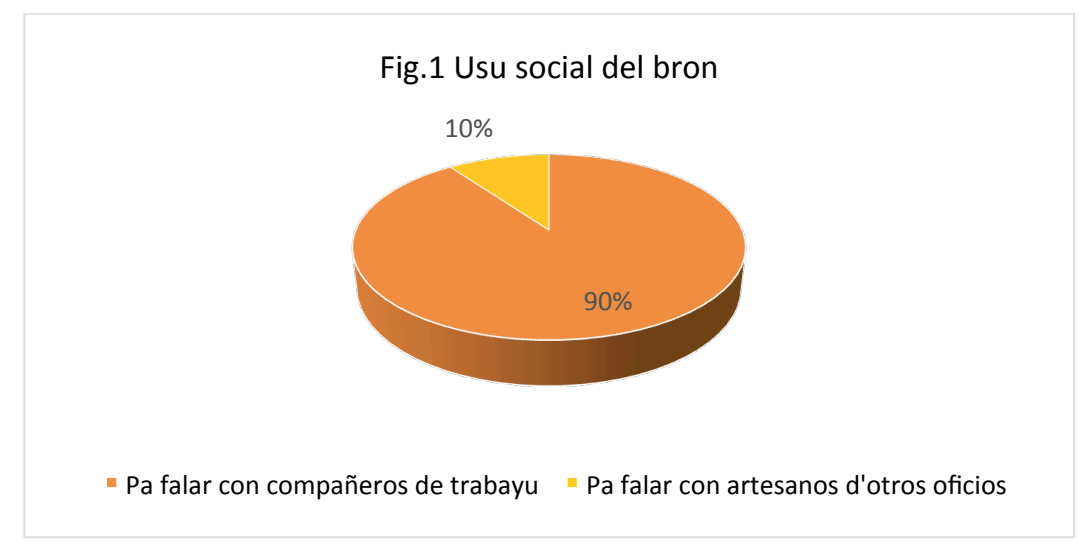

Una gran mayoría (90\%) defiende que'l bron emplegábase fundamentalmente como llingua de trabayu. Mientres un 10\% defende que yera un tipu de fala solo pal llar y que nun pasaba eses llendes, a mou d'un idiolectu familiar, respuesta errónea y que se rexistró nun 30\% (la mayoría homes) de los menores de trentaicinco años ${ }^{23}$, posiblemente como resultáu d'una conocencia escasa de la realidá del bron. De los familiares de caldereros, un 62,5\% (mayoría homes mayores de 65 años, pero tamién homes y muyeres de menor edá) señalen que, magar que yera una xerga de trabayu, llegaba a emplegase en casa. Poro, dellos términos trespasaben l'ámbitu profesional y llegaben a conformar l'idiolectu de les xentes de la zona ${ }^{24}$, pero nunca como sustitutu de la so función nel trabayu.

23 Pue apreciase, por ello, que'1 nivel de conocencia sobre dellos aspectos bási$\cos$ y definitorios de la xerga entama a perdese a midida que lleguen les xeneraciones nueves.

24 Aspectu que yá señaló como frecuente Rodrigues Gomes (2008:23). 
Cabe destacar, nesti sentíu, les opiniones que los mirandinos tienen sobre l'usu o usos de la llingua asturiana, llingua base del bron. Asina, hai que reparar en qu'una mayoría (56,7\%) considera que l'asturianu ye una llingua válida pa tolos rexistros y contestos. D'estos, la metá son descendientes de caldereros, y un $63,3 \%$ considera que tien l'asturianu como llingua materna ${ }^{25}$. Amás, del total d'encuestaos, toles muyeres menos una respondieron que l'asturianu yera una llingua válida pa tolos contestos (ver Fig.2).

Fig.2 Usos de la llingua asturiana por grupos d'edá

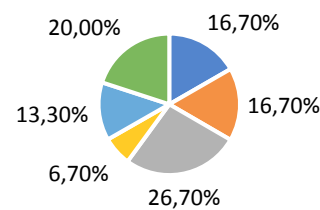

$$
\begin{aligned}
& =\mathrm{HM}<35 \text { válida pa tolos contestos }-\mathrm{HM}<35 \text { usu familiar } \\
& -\mathrm{HM} 35-65 \text { válida pa tolos contestos }-\mathrm{HM} 35-65 \text { usu familiar } \\
& -\mathrm{HM}<65 \text { válida pa tolos contestos }=\mathrm{HM}<65 \text { usu familiar }
\end{aligned}
$$

D'esta muestra, los que defienden que l'asturianu ye una llingua válida pa tolos contestos, respondieron tamién que'l bron yera una llingua pa falar con compañeros de trabayu, y non cor artesanos d'otros oficios. Poro, el nivel de confusión ye muncho menor nestos informantes.

Hai poca conocencia sobre la esistencia del restu de xergues asturianes (ver Fig.3):

Los que desconocen la esistencia d'otres xergues superen (nun 6,6\%) a los que sí saben d'elles. Hai diversidá de rempuestes según los grupos d'edá (ver Fig.4):

25 De los restantes, que nun consideren l'asturianu como llingua materna, la gran mayoría (90,9\%) son el total de los encuestaos más nuevos (grupos $\mathrm{H}<35$ y $\mathrm{M}<35$ ) y un home del grupu H35-65 non descendiente de caldereros 
Fig.3 Conocencia d'otres xergues

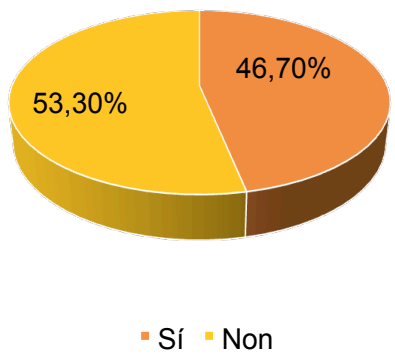

Fig.4 Conocencia d'otres xergues (por edaes)

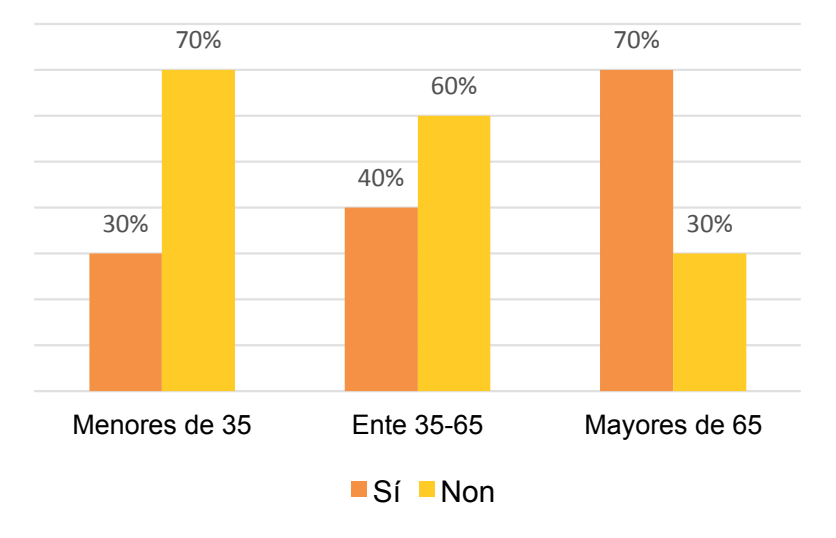

Nos menores de 35 únicamente son muyeres les que creen o saben qu'esisten más xergues n'Asturies, les rempuestes de los varones son, en tou casu, negatives ${ }^{26}$.

26 Dexo fuera d'esta consideración rempuestes que, ensin dexar de ser interesantes sociolóxicamente, nun considero que tengan d'entrar nesti apartáu, al nun tratase de xergues. Esto ye: un 20\% de los encuestaos menores de 35 años señala como xerga el vaqueiro, y otra respuesta, nel grupu de la mediana edá, señala como xerga el gallegoasturianu. Estes consideraciones tienen interés sociolóxicamente, pero nel apartáu nel qu'amueso los resultaos espongo únicamente les rempuestes de criptolectos verdaderos. 
Dientro de los que respondieron sí la xerga más señalada foi la xíriga (nun 92,8\% de les rempuestes). Esta foi, amás, la que conocíen los que namás citaron una: un $60 \%$ de les moces del grupu $\mathrm{M}<35$, un $60 \%$ de los homes del grupu $\mathrm{H}>65$ (incluyendo dalgún familiar de caldereros) y un $20 \%$ de les muyeres del grupu $M>65$ (familiares de caldereros). Les siguientes cítense un númberu de veces mui asemeyáu (el mansolea y el tixileiru), y solo un $20 \%$ de los homes del grupu $\mathrm{H}<65$ citaron siete de les ocho xergues asturianes ${ }^{27}$. Dalgunos, anque nun supieron citar el nome de la xerga, sí supieron señalar la zona d'Asturies de la que yera (ex.: Llanes, oriente d'Asturies, etc).

La gran mayoría de los encuestaos afirmen que'l bron esiste (o esistió n'otros tiempos) fuera de lo que ye la parroquia de Miranda, pero con dificultaes pa señalar el llugar (ver Fig.5):

Fig.5 El bron esiste fuera de Miranda

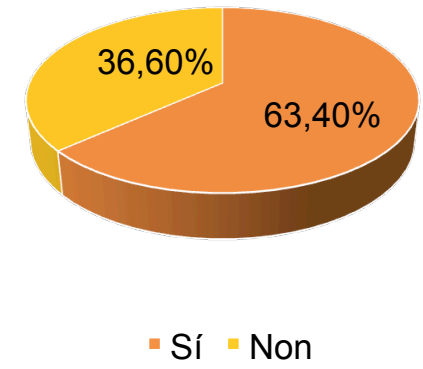

Hai una diferencia clara ente los grupos d'edá: de los menores de 35 años, únicamente un 10\% de los homes y un $20 \%$ de les muyeres respuenden que sí esiste'l fuera de Miranda (un $30 \%$ del grupu en total), pero nun señalen ónde. Amás, hai bastante paridá ente homes y muyeres del restu de grupos d'edá.

27 Esti porcentax nun correspuende a familiares de caldereros, pero sí a xente con conocimientos previos de bron y qu'acudieron a alderiques o conferencies. 
Del grupu d'ente 35 y 65 un $30 \%$ de los homes y un $40 \%$ de les muyeres afirmen que'l bron trespasó les llendes de Miranda, pero namás la metá d'eses muyeres señalen sitiu: Grau (ensin citar la población).

Amás, un $20 \%$ de les muyeres, familia de caldereros, señalen Lleón como otru llugar onde s'alcuentra'l bron. Esta confusión pue debese a dos factores: en primer llugar, el fechu de que Lleón y Castiella yeren rutes comerciales que frecuentaben estos artesanos (Feito, 2002: 36) y, quiciabes, la popularidá d'esta ruta motivara la respuesta. Per otru llau, la confusión pue venir dada d'otra xerga que s'alcuentra en tierres lleoneses y que tipolóxicamente ye mui asemeyada al bron: el burón ${ }^{28}$. Amás, en munches ocasiones considérase'l burón como'l bron del Valle de Forniella.

Dientro del grupu de mayores de 65 años únicamente un $10 \%$ (muyeres y familia de caldereros) nieguen que'1 bron esista fuera de Miranda. Los otros informantes afirmen que sí esistió fuera de la parroquia (ente ellos, el total de familiares restantes de caldereros). D'esi 90\%, un terciu d'homes señalen Grau (siendo un $10 \%$ familia de caldereros), y otru terciu de muyeres concreten que ye en San Xuan de Villapañada ${ }^{29}$. El 20\% restante de muyeres nun son a señalar sitiu, y el 20\% d'homes restante (familia de caldereros) vuelven a señalar Lleón, y la metá d'ellos señalen tamién Francia. La mención del país vecín camiento que ye por conocencia del broun ${ }^{30}$ francés (Feito, 2002: 126).

28 Rodrigues Gomes (2008:319) fai una clasificación tipolóxica o por grupos de les distintes xergues, y precisamente trata de forma conxunta estes dos por topar delles semeyances.

29 Estes muyeres, nenguna de familia de caldereros, acudieron a cursos de bron.

30 De fechu, a lo llargo de la encuesta, son notables les ocasiones nes que los informantes falen d'Auvernia, rexón onde se daba'1 broun, una xerga d'albañiles. 


\subsection{Interés social pol bron}

Teniendo en cuenta la esistencia, años atrás, de cursos, conferencies y actividaes relacionaes cola historia de la calderería y de la xerga (ver Fig.6):

Fig.6 Asistencia a cursos o alderiques sobre'l bron

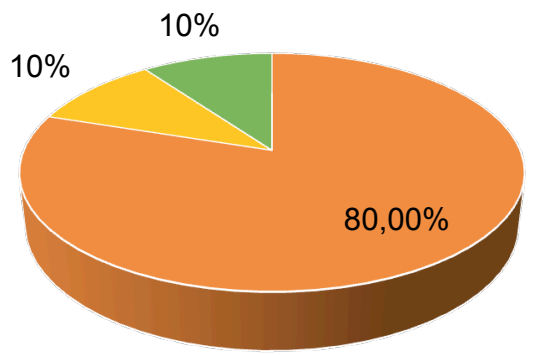

- Non " Alderique - Cursu

L'interés intelectual por conocer daqué sobre'l bron ye mui escasu (ver Fig.7). Nengún familiar de caldereros acudió nunca a nin a un alderique nin a un cursu, como la mayoría del restu de los informantes. Únicamente un $10 \%$ del total (40\% de les muyeres y un $20 \%$ de los homes mayores de 65 años) estudió bron, mientres qu'otru $10 \%$ (un $20 \%$ d'homes mayores de 65 y un $40 \%$ d'homes menores de 35) fueron a dalguna conferencia. Nun paez qu'haya interés n'afondar nos conocimientos sobre'l bron, pero contradiz les demandes que los mesmos mirandinos faen más alantre.

En xeneral, la disposición de los informantes por acudir a charres, alderiques o cursos ye inexistente tamién pa les otres dos llingües existentes en Miranda: asturianu y castellanu. La mayoría (66\%) nun tien ningún interés, del mesmu mou, nun hebo nenguna rempuesta qu'amosara un interés por dir a cursos, conferencies o alderiques namás sobre l'asturianu. De los 
que respondieron sí, sobre l'asturianu y sobre'l castellanu la mayoría $(71,5 \%)$ yeren muyeres. Amás, el $50 \%$ de los descendientes de caldereros, respondieron sí, sobre l'asturianu y sobrel castellanu (ver Fig.7).

Fig.7 Asistencia a cursos o alderiques sobre'I castellanu o asturianu

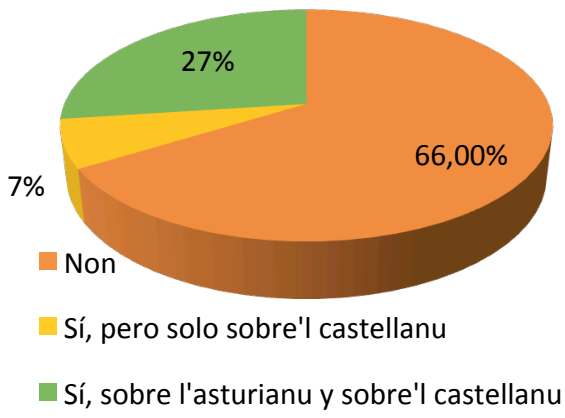

\subsection{Conocimientos del bron que perviven nos mirandinos}

La mayor parte de los informantes nun poseen conocimientos de bron $(60 \%)$, pero sí poseen una cierta competencia llingüística casi la metá ${ }^{31}(40 \%)$ (ver Fig. 8 ).

De los menores de 35 años nengunu respondío sí o sí, daqué. Los grupos de mediana edá únicamente ufren un 20\% de rempuestes afirmatives parciales (un 10\% de muyeres y un $10 \%$ d'homes). En cambiu, nos grupos de mayor edá el $90 \%$ de los informantes almite tener competencia llingüística en bron ${ }^{32}$, pero únicamente un $30 \%$ afirma manexar completamente la xe-

31 El cuestionariu inicial únicamente contemplaba dos rempuestes: sí y non pero, a la vista de les consideraciones que fueron faciendo los informantes al responder, decido amestar equí la opción Sí, daqué ya que, en munches ocasiones, los informantes yeren a falar o contar daqué na xerga, y almiten emplegar términos del bron con frecuencia, pero nun s'identificaben con un sí total.

32 El 10\% de muyeres que caen fuera d'esta afirmación son familiares de caldereros, y afirmen conocer namás dalguna palabra. 
rga. De los que respondieron $n o n^{33}$ poco más d'una cuarta parte (26,3\%) tendría interés por deprender; especialmente nel grupu de muyeres menores de 35 años (un 60\% d'elles), y una parte mayoritaria $(73,7 \%)$ nun muestra interés.

Fig.8 Competencia en bron (saber falar bron)

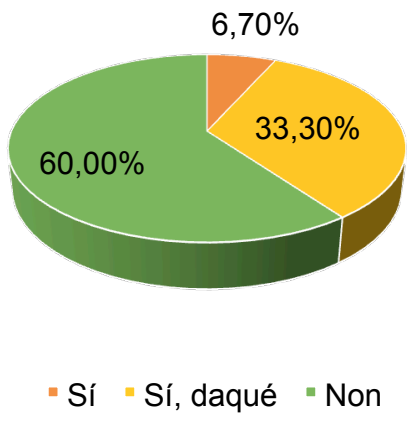

Pidíase tamién a los informantes, previa respuesta de sí o non, qu'enunciaran trés palabres en bron. La respuesta xeneral foi (ver Fig.9):

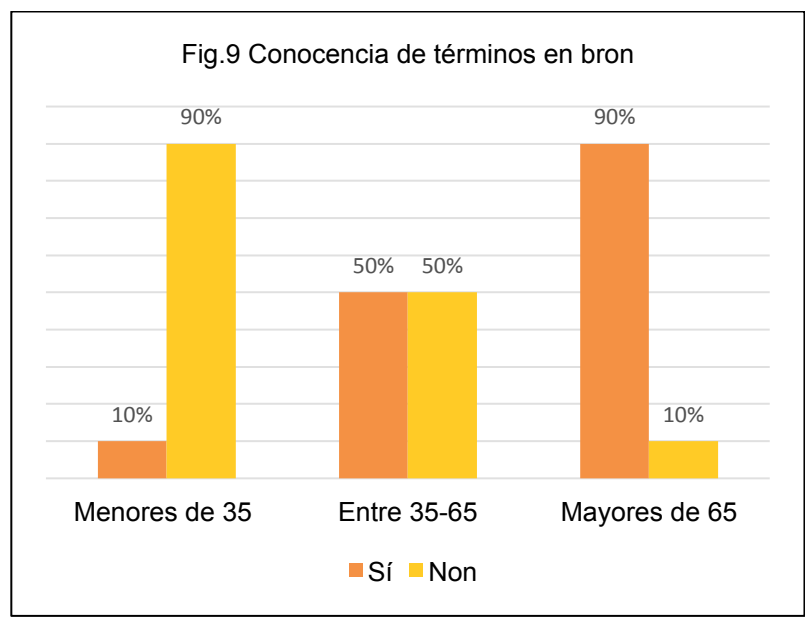

33 Incluyo equí a una muyer del grupu M35-65 qu'almite que, de neña, sabía falar daqué y que davezu falábase en casa. 
El mayor númberu d'informantes que conocíen términos foron d'edá más avanzada (un 90\%). El grupu de mediana edá colocóse nun puntu intermediu (un 50\%) y los menores de 35 años nun conocíen (nun 90\%) ningún términu en bron. De los homes entrevistaos, un $60 \%$ conocíen dellos términos (por grupos d'edá: $\mathrm{H}<35,20 \%$; H35-65, 60\% y H>65, 100\%). De les muyeres, un $40 \%$ conocíen palabres en bron (por grupos d'edá: $\mathrm{M}<35,0 \%$; $\mathrm{M} 35-65,40 \%$ Y $\mathrm{M}>65,80 \%)$. A midida que les xeneraciones son más nueves, los elementos del bron van perdiéndose. Nes xeneraciones más vieyes sigue calteniéndose una cierta competencia o reminiscencies léxiques frecuentes. Ye un exemplu de transición xeneracional y de perda progresiva del bron.

A los que respondieron afirmativamente, pidióse-yos qu'enumeraran trés palabres. Estes fueron: piltra ${ }^{34}$ 'cama' ( $\left.\mathrm{x} 2\right)$, xagó 'calderero', 'amigu', 'compañeru' (x5), xinclar 'baillar', 'blincar', guaño/a 'chico'/'chica' (x5), trobar(se) ${ }^{35}$ ( $\left.\times 4\right)$, allupar 'ver', 'mirar' (x3), clarencia ${ }^{36}$ 'lluz', 'salud'(x2), tonesca37 'botella' (x2),

34 Doila por válida ya que, a pesar de que ye tamién común en ciertos rexistros del castellán como viniente del llinguax carcelariu, los dos informantes que la citaron amestaron la observación de que tamién esiste en bron, al marxe del castellán.

35 Trobar(se)/ trovar(se) ye un verbu comodín que pue significar 'falar, 'tener', 'tar', 'ser', 'afayar/-ase', 'alcontrar/-ase', 'quedar/-ase', 'ocupar', etc., dependiendo del contestu.

36 El términu taba recoyíu yá nel vocabulariu d'Aurelio de Llano (1921) y tien más acepciones ('vida', 'orixen', 'alma', etc), pero únicamente lu rexistro coles dos mentaes.

37 Dientro de la espresión tonesca de bayo 'botella de vinu'. Recueyo tamién una variante con $u$ (tunesca), que posiblemente se deba a una confusión de vocales velares o zarramientu d'átones non finales (García Arias, 2003:18) 
$\operatorname{xirapa}^{38}(\mathrm{x} 2)$, xirina (dim. Xira ${ }^{39}$ 'belleza'), maura 'caldera', xeva 'vieya' muít 'boca', vixaos 'güeyos' (x2), macayu ${ }^{41}$ 'cigarru', 'tabacu', xipar 'mexar', ñácara 'cara', suquir 'comer', padela 'sartén', utana 'iglesia', paina 'muyer del payo', 'payina', guilfo 42 'pioyu' (x2), pilesa (x2), munquir ${ }^{43}{ }^{\prime}$ comer' $^{\prime}(\mathrm{x} 2)$, hartonero 'panaderu', espillar $^{44}$ 'estudiar', garliar 'falar', xagotera 'natural de Miranda', esgolmar 'fuxir', estafar 'matar' y romaxa 'fiesta', 'romería. Munchos d'estos términos lleven a significaos del ámbitu de los tabús. Quiciabes l'emplegu o la frecuencia d'estes formes -nel casu de los homes- tea relacionada cola noción del prestixu encubiertu (López, 2004: 296).

Sobre si tienen usu actualmente y s'empleguen na fala familiar (ver Fig.10):

38 Xirapa — camiento que como variante de xarapa - nun se recueye nin en Aurelio de Llano (1921) nin Feito (2002). Pue ser, nesti casu, que se deba a una confusión de los informantes, quiciabes obedeciendo a la inestabilidá xeneral del vocalismu átonu non final (García Arias, 2003:19). La etimoloxía paez ser la mesma qu'ast. xarabe y cast. jarabe y sirope, ye dicir, el llatín medieval syrupus y esta del árabe sarap (DRAE). Ye la primer constancia de la esistencia de la voz xarapa en bron.

39 Xira ye un términu creáu modernamente nos cursos de bron; por ello, Feito (2002: 301) precédela d'un \#, como tolos términos que se crearon del mesmu mou.

40 Muí ye tamién una voz caló, pero la informante amuesa conocencia de que tamién ye propia de la xerga.

41 Recueyo la forma con - $u$ que recoyía tamién A. Llano (1921), y non macayo 'tabacu' que foi creada modernamente y que Feito recueye precedida de \#.

$42 \mathrm{Na}$ espresión guilfos en la filesa 'pioyos na cabeza'. La voz filesa nun ta recoyida en nengún vocabulariu de bron; la palabra de referencia ye, polo xeneral, mocha. Pue tratase, bien d'una variante léxica, bien d'una confusión per parte de los dos informantes cola voz filosa 'camisa', recoyida en dellos vocabularios.

43 Recueyo tamién una variante munquir que nun apaez en ningún vocabulariu y, quiciabes, se deba a una confusión del informante.

44 Recuéyolu namás con esti significáu, pero ye ún de los verbos que poseen abondes acepciones. 
Fig.10 Emplegu de delles voces

$13,33 \%$

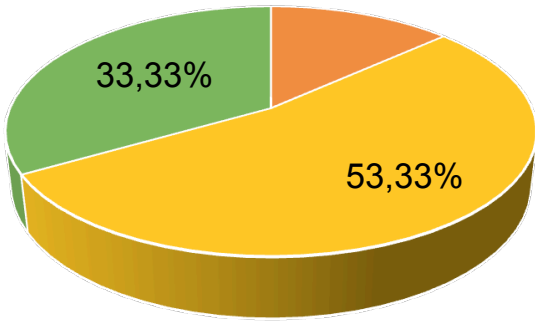

" Non "Sí "A veces "

Les más habituales son: xagó, guaño, guaña, trobar(-ase) y allupar, que paecen ser les que tienen un tovía usu frecuente. Esto tien una esplicación histórica: trespasaron la llende de lo secreto y llegaron a la llingua común, hasta pue dase'l casu de que consigan sustituir la palabra primera ${ }^{45}$, como pasa con otres xergues (Álvarez, 2005:39).

Merez la pena reparar en que, en munches de les xergues, la palabra pita conozse como gumarra, voz con un orixe non del too conocíu pero que s'estima que vien del caló o xermanescu (García, 1975: 397). El númberu d'informantes familiarizaos cola voz gumarra ye (ver Fig.11):

La mayor parte de los encuestaos nun supo responder, mientres qu'una informante (del grupu $\mathrm{M}<35$ ) consideró que yera la mesma forma que la del castellanu, inválida por tanto pa esti cómputu. De los que respondieron correctamente, un $60 \%$ son homes (20\% de grupu H35-65 y 40\% del H>65). D'estos homes,

45 Na descripción del burón l'autor destaca los términos relacionaos colos nomes d'animales, persones, sexu y otros verbos frecuentes como ser, tar, comer, beber... 
namás un $20 \%$ ye familia de caldereros ${ }^{46}$. Les muyeres que respondieron correctamente ( $40 \%$ de mayores de 65$)$ fueron a cursos de bron, al igual que l'home restante de los dos mayores de 65.

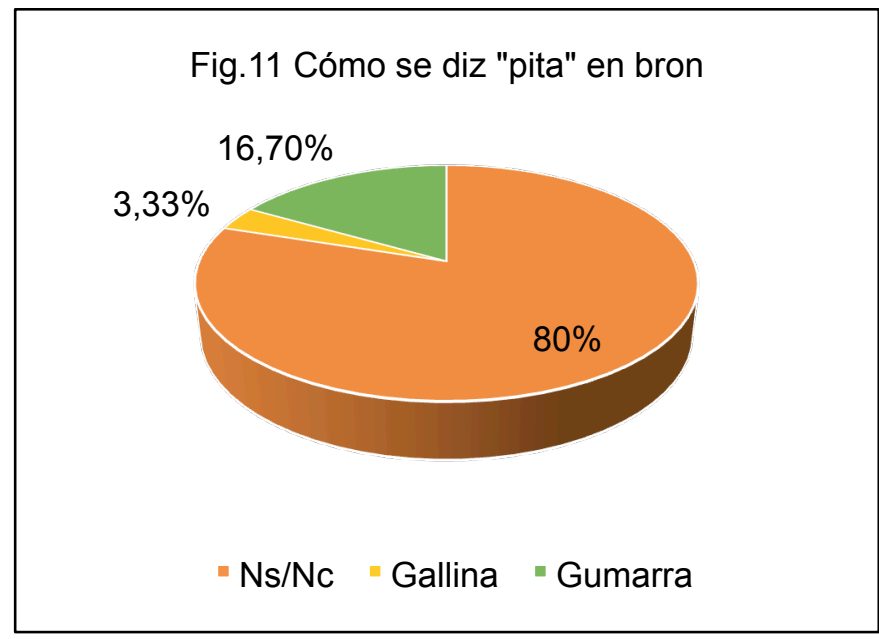

Ensin salir del planu léxicu, pente medies de la llectura d'una riestra de nueve palabres del bron recoyíes de los pallabreros publicaos nos últimos años, pretendíase comprobar si los informantes yeren quién a reconocer dalguna. En munches ocasiones, ante la pregunta abierta qu'exixe citar dalguna palabra, esi saber enciclopédicu nun s'activa. Por ello, consideré interesante comprobar si reconocíen les siguientes palabres y, al empar, si yeren a desplicar el significáu de dalguna de les que señalaran. El nivel de conocencia, por grupos d'edá, sedría'l siguiente (ver Fig.12):

A midida qu'aumenta la edá de los informantes, la conocencia de palabres tradicionales del bron tamién crez. A escepción de términos como matina onde hai que sumar el fechu de que pue ser conocida por ser italianismu ${ }^{47}$. Les más conocíes son los

46 Fíu de Luis Muñiz Suárez "El Catalín", ún de los últimos caldereros de Miranda (Feito, 2002:79).

47 Vien de mattina 'mañana'. 


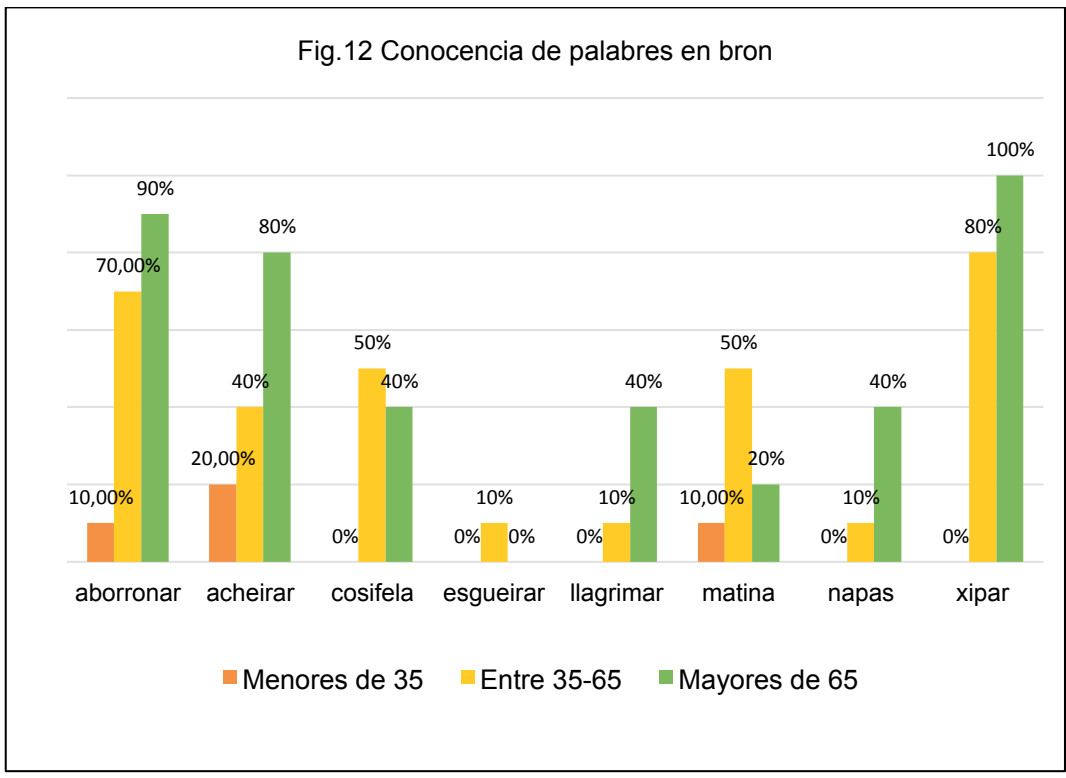

términos que s'emplegaben pa realidaes desagradables: xipar 'mexar', aborronar 'fumar/quemar' o acheirar 'goler mal', palabres que conocieron tolos familiares de caldereros. Llagrimar 'llover', napas 'ñalgues', o esgueirar 'marchar corriendo' nun se rexistren cola mesma vitalidá. Sobre cosifela, un 33,3\% de familiares de caldereros (homes mayores de 65 años) comenten que ye voz creada modernamente y de poco usu tradicional ${ }^{48}$. Trataríase de neobrón, al igual que parroquiunfa ${ }^{49}$ y archivifel.

La preba siguiente consistió na identificación d'un testu. Teníen d'escoyer, xustificadamente, qué testu taba en bron y, si yeren quien, dicir la xerga de los otros dos (mansolea y xíriga). Un $40 \%$ reconocieron el testu en bron, col repartu (ver Fig.13):

48 Feito (2002: 329) señálala como recoyida en Miranda con posterioridá al vocabulariu d'Aurelio de Llano.

49 En cambiu, en Feito (2002:36) vien recoyida non como creación, sinón como tradicional. Amás, consta la convicción relixosa que caracterizaba a los caldereros. 


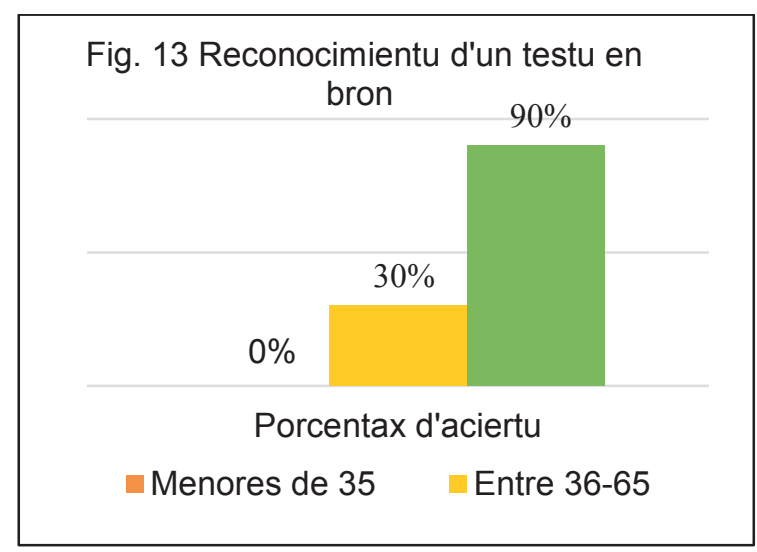

Pero nengún informante consiguió reconocer les xergues de los dos restantes, magar qu'anteriormente señalaran la esistencia de la xíriga o d'otres xergues. Na mesma llinia, apurrióse-yos un testu íntegramente en bron, pa comprobar el nivel d'intelixibilidá que-y asignaben, independientemente de la competencia llingüística (ver Fig.14):

Fig. 14 Comprensión d'un testu en bron

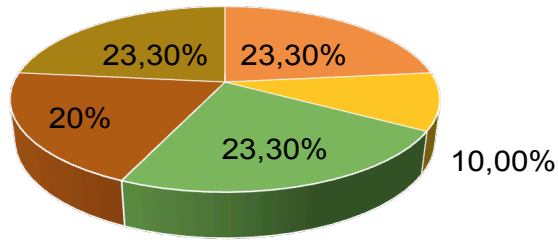

- Si, too

- Non, nada

- Sí, la mayor parte

- Non, casi nada

- Más o menos 
El repartu por edaes sedría: (ver Fig.15):

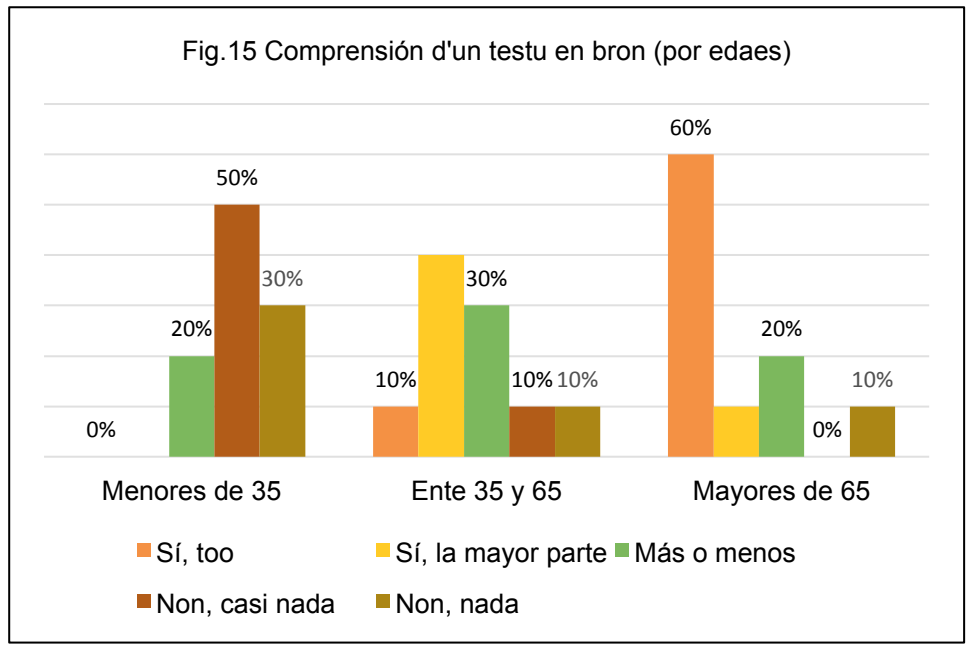

Los informantes d'edá más avanzada son a entender gran parte del testu, y el $85,7 \%$ del total de los que respondieron Sí, too son mayores de 65. Nos más nuevos les rempuestes comunes son Non, nada, y Non, casi nada. Del total de los que comprendieron el testu na so totalidá o na so mayor parte, un $57,1 \%$ son familia de caldereros.

Paez xustificable considerar que'l bron, a pesar de que como xerga gremial desapaeció col oficiu, fai un influxu apreciable na forma de falar de les xentes de Miranda. A pesar del evidente estáu de regresión, paez nun tar esta tan escaecida como otres xergues asturianes como'l tixeleiru o'l maconeiru (Álvarez, 2006:108).

El 63,3\% de los encuestaos consideren l'asturianu como llingua materna. El 100\% de los informantes conoz y entiende l'asturianu. Les diferencies más destacables alcuéntrense na llectura y a la escritura, diferencies que nun se dan nel castellanu: el 100\% de los encuestaos fálenlu, escríbenlu y entiéndenlu (ver Fig.16).

Como queda reflexao nel gráficu, son los grupos HM35-65 y $\mathrm{HM}>65$ los que falen más asturianu $\mathrm{y}$, concretamente, nel grupu 


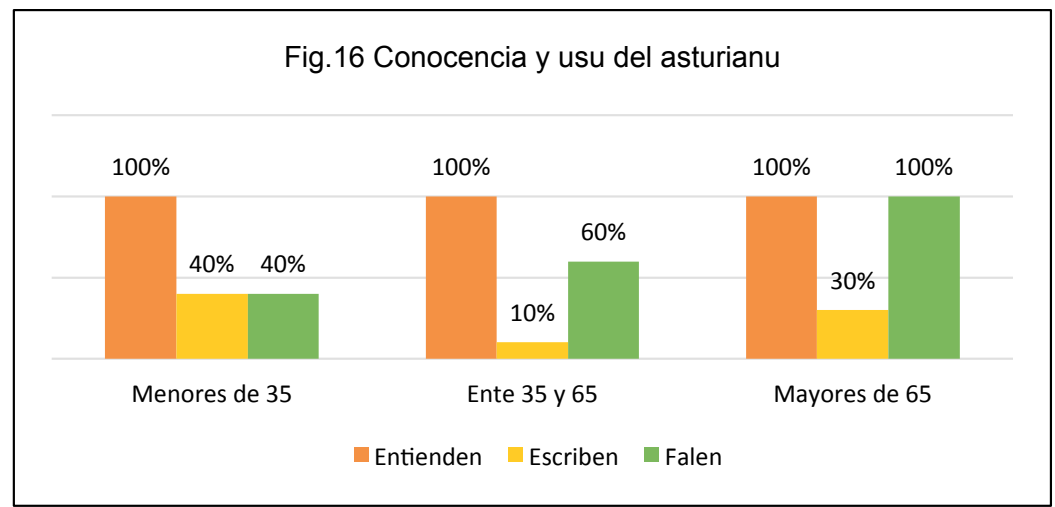

$\mathrm{HM}>65$, tolos informantes respondieron afirmativamente. Nel grupu de mediana edá, falen más asturianu los homes que les muyeres ( $40 \%$ d'homes y $20 \%$ de muyeres), incluyéndose'l total de fíos de caldereros en dambos grupos. Equí hai que destacar un aspectu: los que más asturianu falen, más bron conocen y más términos en bron empleguen (compárense Figs. 8 y 16). Si un 90\% de los informantes de los grupos HM35-60 y HM>65 afirmaben falar daqué de bron, un $80 \%$ de los mesmos afirmen falar asturianu. Nos menores de 35 (ver Fig. 9), el 90\% respondiera que nun conocía ningún términu en bron, y son tamién los que menos asturianu falen ${ }^{50}$.

Llama l'atención el fechu de que, sicasí, son los menores de 35 años los que más asturianu escriben. Esto desplícase en tanto qu'estos menores que respondieron afirmativamente, estudiaron toos llingua asturiana na escuela, y conocen les normes ortográfiques. Los mayores, per otru llau, nun paecen identificase coles normes ortográfiques del asturianu, anque un $70 \%$ de mayores de 65 años, menten que tampoco tienen una conocencia grande de les normes del castellanu.

50 Asina, paez qu'hai una relación directamente proporcional ente la conocencia y usu del bron y del asturianu: amás conocencia d'asturianu, más conocencia de bron y viceversa. La perda de la identidá llingüística asturiana, llingua base del bron, trai una perda de la competencia y conocencia de la xerga. 


\subsection{Valoraciones sociales del bron: ¿esiste estigma llingüís- ticu? \\ Los artesanos de los gremios taben estigmatizaos socialmen- te, especialmente fuera del llugar. Equí trato d'atopar cuála ye la situación actual y constatar si, efectivamente, la xente tien cono- cencia sobre esti fechu históricu (ver Fig.17).}

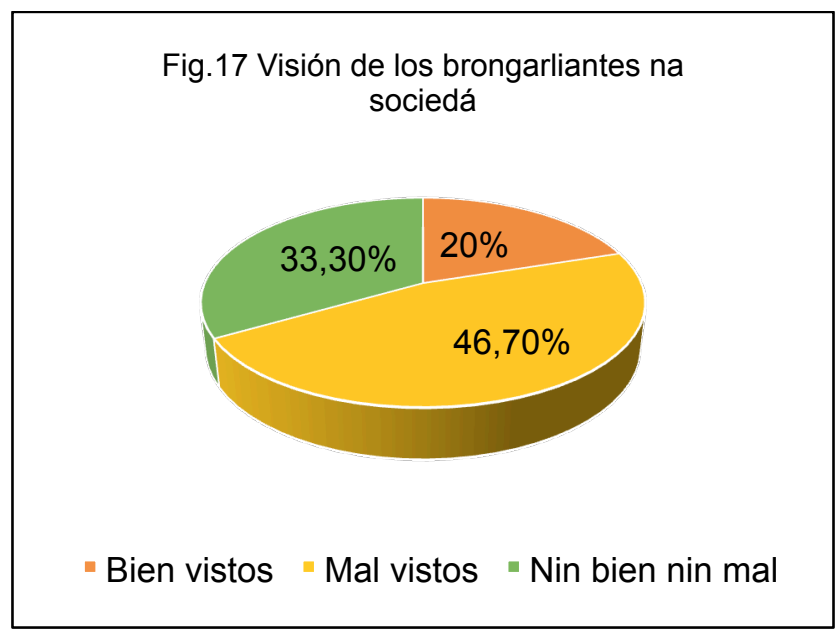

Un $46,7 \%$ considera que los usuarios del bron teníen una consideración social mala. Otra parte $(33,3 \%)$, nun cree na estigmatización, pero tampoco nuna consideración positiva. Nin la cuarta parte $(25 \%)$ considera que la consideración yera bona. Nos familiares del cadereros, un 12,5\% defendió que los caldereros habíen de ser xente bien valorao socialmente. Pero $25 \%$ nun piensa que la consideración social fuera nin mala nin bona y, finalmente, más de la metá $(62,5 \%)$ afirmen que, en contestu gremial, la consideración yera bona, pero fuera del grupu y de Miranda, la estigmatización crecía. Esto defiéndese en dellos estudios antropolóxicos, como los de Fidalgo Santamariña, onde se diz que los artesanos yeren oxetu d'una visión mui negativa naquellos llugares nos que se desplazaben pal comerciu (Rodrigues, 2008:31). Al ser la xerga un trazu fundamental d'esi grupu, pue falase de qu'esistió 
un estigma llingüísticu. Pero sincrónicamente nun pue defendese porque, a pesar de qu'haya cierta conservación, la función social de la xerga desapaeció al desapaecer la profesión de la calderería.

\subsection{Usos actuales del bron: espontaneidá, pervivencia y lleenda}

La gran mayoría, un $80 \%$ (HM>65) consideren que sí perviven actualmente términos en bron y que s'utilicen falando normalmente. Una parte considerable $(63,7 \%)$ pudieron citar delles voces - y que se repiten con frecuencia nún y otru informante-: xagó 'compañeru' (x7), raso 'cura', garo 'pueblu' (x2), gruño 'go$\mathrm{chu}^{\prime}$ (x3), guaño ${ }^{51}$ 'mozu' (x5), trobar(-ase), tonesca ${ }^{52}$ 'botella' ( $\left.\mathrm{x} 2\right)$, prois 'culu', ñácara 'cara' (x2), icho 'sí', xiro/a 'guapu', 'prestoso'

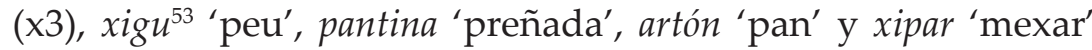
(x2). La mayoría señalaron que, a pesar de que tienen vitalidá, tán fuera de la competencia de los mozos, nun formen parte del so argot o lectu ${ }^{54}$. Cabe poner esto en relación cola situación de la xíriga de Llanes, onde tamién ta constatada la vitalidá de delles voces de la xerga de los teyeros, que s'empleguen mezclaes cola llingua asturiana, sobre manera nos descendientes de teyeros (Martín, 2004:101).

Nun fai falta añadir, llegaos a esti puntu, que la totalidá de la muestra tenía conocencia de la esistencia del bron. Sí varíen los móviles polos qu'algamaron conocencia tala. En xeneral, débese al raigañu cultural. Los descendientes de caldereros conocen el bron per vía familiar. Amás, un 76,7\% de los informantes señalen

51 Parte de los informantes citó'l términu na fras El guaño que se troba.

52 Siempres, según los informantes, na construcción tonesca de bayo ‘botella de vinu'.

$53 \mathrm{Na}$ espresión chantar xigos 'tirar peos'.

54 Cola escepción d'únicamente un informante que defendía que la voz xipar siguen emplegándola nos círculos de la mocedá. Nun rexistré equí nengún usu que contraste esta información. 
el llabor de D. José Manuel Feito, que se preocupó pola conocencia histórica de la xerga y pola so recuperación, hasta convertise na figura más reconocida con respectu al bron de Miranda.

N'últimu llugar, traté de rexistrar anécdotes, cuentos, lleendes, dichos o cualquier elementu popular que tuviera'l bron o a dalgunu de los sos falantes como protagonista. Nun alcontré nenguna consideración d'esti calter nel grupu de los menores de 35 años nin nos d'ente 35 y 65 . Nel grupu restante, más de la metá $(60 \%)$ refirió dalguna anécdota. Hebo trés referencies al fechu de que la denominación del bron pa la fala de los caldereros tien el significáu de 'mentira, 'engañu' dientro de la mesma xerga. Per otru llau, una de les muyeres, familia de caldereros, recuerda que yera vezu contar un chiste que falaba de les partes d'una caldera relacionándoles colos muérganos sexuales del home y la muyer $^{55}$. Nun rexistré nenguna referencia a la enemistá ente los artesanos caldereros y los tamargos del oriente, que tien esistencia probada (Feito, 1977: 71).

Pero l'oxetivu yera dar con una lleenda que paez cuasi conxénita a les xergues de la Península: dos artesanos (d'un gremiu determináu), tando fuera del so llugar, entamen a falar na xerga pa criticar daqué o dicir improperios a una moza y, cuando creen que naide ta entendiéndolos, respuénde-yos daquién na so xerga. L'enseñu que se desprende d'esti tipu de lleenda ye cenciellu: hai que tener cuidáu al falar, porque daquién pue entendete na to fala secreta onde menos lo esperes (Rodrigues, 2008:33). Esta lleenda, manteniendo la base, adáptase a les xergues, con cambios pequeños nuna y otra xerga ${ }^{56}$.

Nel casu del bron, rexistré solo una vez la lleenda que siguía'1 modelu de les que cita Rodrigues Gomes. La informante (mayor de 65 años y familia de caldereros) refirió una hestoria na que dos

$55 \mathrm{La}$ informante nun foi a recordar el cuerpu del testu al que se refería. Poro, dexo constancia d'ello, pero nun pueo ufrir una trescripción del mesmu.

56 Rodrigues Gomes op.cit. cita cinco exemplos d'esta lleenda, pero nun refier nengunu específicamente del bron. 
caldereros, en Francia, van a xintar nun bar y, al probar el pan, ún diz-y al otru: Atesco artón tróbase canelo 'Esti pan ta duru'; al pocu, el camareru volvió con otros bollos de pan, y contestó-yos na so fala: 'Preba esti otru a ver si ta tiernu'.

Esta hestoria sigue los trazos xenerales d'esti tipu de lleendes: allugamientu n'otru llugar, presentación como un fechu real ${ }^{57}$ y mensaxe moral. La fonte histórica ye siempres el testimoniu d'ún de los que la protagonicen, que nunca ye tresmisor directu (Gomes, 2008:35). Rexistré otres dos lleendes, pero nun participen del mesmu grau de semeyanza cola lleenda base a la que me referí enantes ${ }^{58}$.

\subsection{El bron como seña d'identidá de los mirandinos}

Una mayoría casi absoluta (97\%) considera'1 bron como un elementu identitariu de Miranda y los mirandinos, cola escepción namás d'un home menor de 35 años. Si comparamos col fechu de que'1 $60 \%$ de los menores de 35 y un $40 \%$ de los informantes de mediana edá respondió nun falar asturianu (ver Fig. 16), taríemos ante la preba de que'l bron ye una seña d'identidá mirandina independientemente de la conocencia o o' la estima a la llingua asturiana.

Sobre si tien qu'haber testos en bron nes publicaciones de la zona, les rempuestes fueron les siguientes (ver Fig.18):

57 La informante conoz la hestoria porque-y la contara so pá.

58 Les otres dos lleendes que rexistré pal bron son les siguientes: (1) Nuna partida de cartes, nun chigre de Miranda, ún de los que xugaba taba faciéndose pasar por mudu, y mientres los otros falaben en bron y dicíen improperios, ún de los caldereros aprovechó pa facer trampa nel xuegu, y entós el mudu faló (en bron) p'alvertir al restu de xugadores. (2) Un mozu (que l'informante cita comól ñetu de Manuel Azaña, presidente de la Segunda República) yera profesor en Valdepeñas (Ciudad Real), y un día, al salir de clas dixo, en bron: Moi esgolma festar [sic] 'Voi facer de vientre'. Entós, otra de les profesores (que l'informante cita como tía de so) respuende: $i$ Que te aproveche! Nun les considero na mesma midida que la citada más arriba por allugase na propia Miranda (la primera) o ser demasiado cercana al tiempu actual (la segunda). Amás, nun consta d'esti tipu nenguna lleenda nos estudios académicos. 
Fig.18 Demanda de testos en bron nos medios de la zona

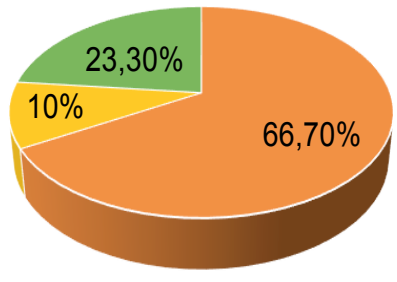

-Sí $\quad$ Non $\square$ Indiferente

Mui percima de la metá $(66,7 \%)$, los mirandinos demanden presencia de testos en bron nes publicaciones de la zona, señalando que, onde yá apaecen, quieren que sigan apaeciendo. De les rempuestes negatives, la mayoría correspuenden a los menores de 25 y únicamente homes. La tendencia xeneral ye al interés pola llectura de testos en bron o, al menos, pola posiblidá de que s'ufran. La totalidá de familiares de caldereros reconocen la importancia de qu'esto seya asina.

La inmensa mayoría defende que ye importante dar a conocer la esistencia del bron y de les xergues. El 90\% de los mirandinos consideren fundamental que nos centros educativos los profesores dean a conocer la esistencia d'estes xergues, como contribución a la educación fuera de les llendes del curriculum académicu. Únicamente un 10\% (homes menores de 35 años) considera innecesaria esa mención per parte de los profesores. Sí hai diversidá d'opiniones sobre la espansión xeográfica d'esta demanda educativa (ver Fig.19):

La mayoría (63\%) cree qu'esti llabor per parte del profesoráu ha d'estendese a tol Principáu d'Asturies. D'ellos, los que yá señalaren la esistencia d'otres xergues asturianes, reclamen lo mesmo con respectu a estes. Otra parte (11\%) prefier facelo estensivo 


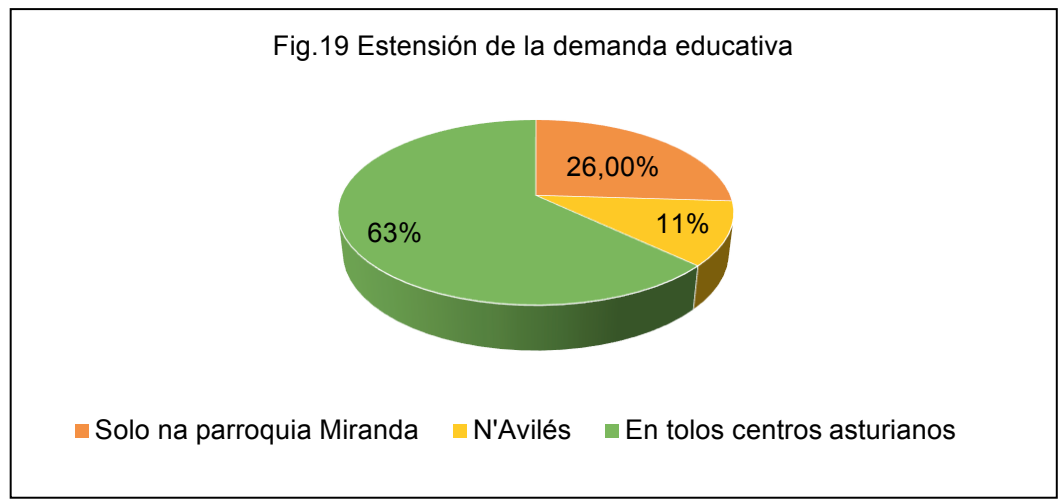

a Avilés, pero ensin salir d'eses llendes, mientres otra parte (26\%) considera que ye relevante, únicamente, na parroquia de Miranda. Los qu'escoyeron esta respuesta, aparte de los menores de 35 (un 30\% d'ellos) fueron la metá de los familiares de caldereros. Hai una tendencia clara, nos más vinculaos al falaxe familiarmente, a que l'ámbitu territorial del bron nun supere les llendes de la parroquia mirandina, como asocedía na época histórica d'usu y vitalidá del bron como xerga.

Siguiendo nesta llinia, frente al 90\% d'informantes que defendíen la presencia de bron nes escueles, un $86,7 \%$ considera que tamién tien ye importante la presencia del asturianu. Sicasí, dientro d'esta mayoría, hai informantes (15\%) que sí sofitaben la presencia de bron nel aula, pero non la del asturianu. Esto ye, la gran mayoría de la xente encuestao demanda l'asturianu nes escueles, pero hai informantes que, anque defienden el bron, nun tán a favor de la presencia d'asturianu como asignatura. Estos, de toes formes, son una minoría, y suponen namás un 13,3\% del total de la muestra.

Casi siete de cada diez mirandinos (66,7\%) considera que'1 bron ha de cuntar con sofitu institucional al ser un elementu históricu de Miranda. Una parte restante (33,3\%) nun considera que la xerga tenga de gozar de protección.

Dientro d'esti sector contrariu a la protección, más de la metá (60\%) son menores de 35 . Nun s'aprecia un grau d'interés como 
nes otres xeneraciones ${ }^{59}$. Del mesmu mou, dientro del grupu de mediana edá, ye un $30 \%$ el que consideró que tampoco tien de gozar de nenguna protección. Poro, ye namás un 10\% de los mayores de 65 años el que fai consideración tala, colo que'1 90\% sí cree qu'ha gozar de promoción y protección. Asina, apréciase cómo, a midida qu'avanza la edá de los informantes, crez l'interés pola protección del bron (ver Fig.20):

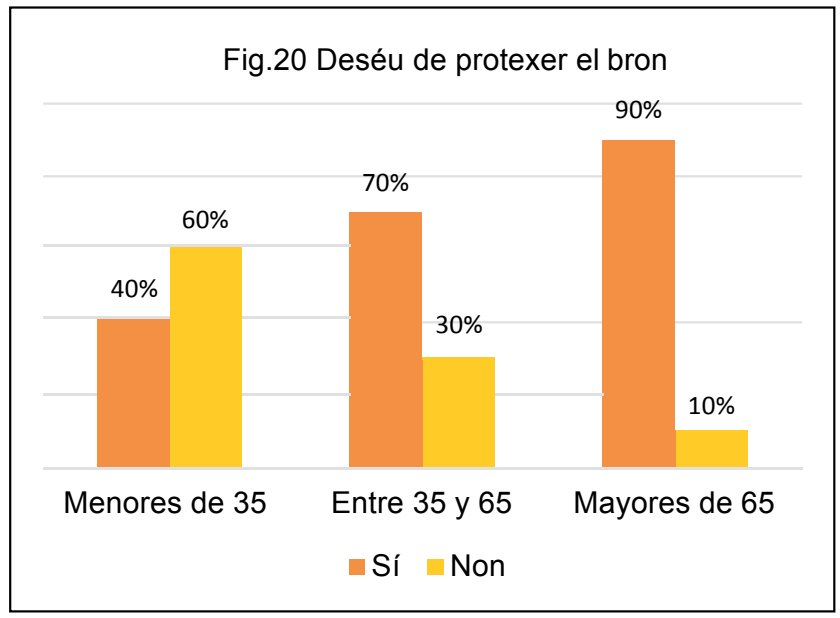

Partiendo d'un predominiu claru nos más nuevos d'una respuesta negativa ante la demanda de protección de la xerga, apréciase un ascensu na postura defensora a midida qu'avanza la edá de los informantes. Finalmente, les postures iniciales acaben totalmente invertíes. Al mesmu tiempu, en tolos grupos d'edá, son los homes (especialmente los más nuevos) los que muestren una mayor rocea al sofitu institucional de la xerga (ver Fig.21):

$59 \mathrm{Si}$ se fai comparanza d'esta situación cola de la llingua asturiana, vense resultaos curiosos. Según l'estudiu de Gema Cuesta na Pola Ḷ̣ena (2016:162), los más nuevos paecen presentar un nivel de compromisu de conciencia llingüística al empar que faen más usu de trazos asturianos. Equí, la situación ye totalmente contraria: aparte de ser los que menos caltenimientu del bron amuesen, son tamién los que menos interés cultural y deséu de protección demanden. 
Fig.21 Respuesta "non" según sexos

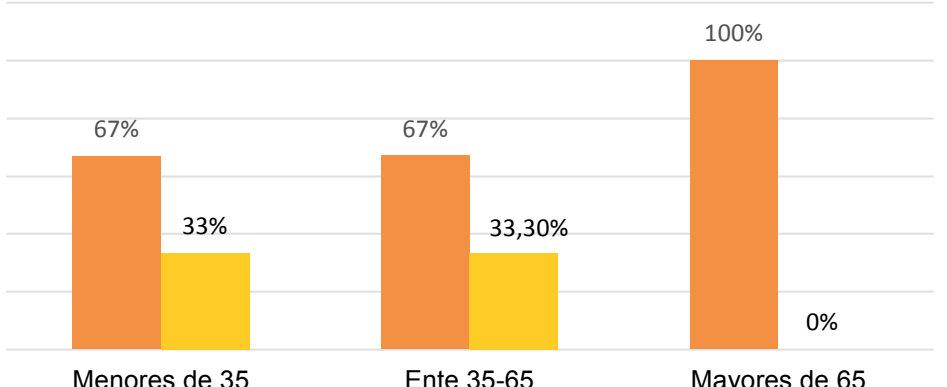

Menores de 35

Ente 35-65

Mayores de 65

-Homes Muyeres

Per otru llau, únicamente'1 10\% de mayores de 65 años se muestra negativu al sofitu y a la protección del bron. En cambiu, los qu'acudieron a cursos o alderiques temátiques, siguen calteniendo esi interés cultural y demanden protección (100\%).

Tovía na llinia de relación ente'l bron y les instituciones intentóse facer una evaluación del nivel de compromisu pa cola protección del bron de les distintes instituciones o organismos (públicos y privaos) que tienen relación con Miranda. Asina, depués de les valoraciones de los informantes (del 1 al 5), los resultaos xenerales, fecha la media aritmética, son (en base 5), de más valoráu a menos valoráu: 1) Parroquia de Santo Domingo de Miranda: 4,36. Señalen los informantes la iniciativa y el llabor de D. José Manuel Feito. 2) Asociacion de Vecinos de Miranda de Avilés: 2,6 y 3 ) Casa Conceyu d'Avilés: 1,5. Poro, hai una demanda xeneralizada d'una mayor implicación per parte del organismu de gobiernu d'Avilés. A escepción de los que destaquen (13\%) la participación na organización de les Xornaes de llingües gremiales d'Avilés ${ }^{60}$.

Teniendo en cuenta la demanda xeneralizada de presencia del bron nes aules (como información a los escolinos sobre la 
esistencia de la xerga), la consideración como elementu cultural venceyáu a Miranda (o Asturies si se fala de xergues en xeneral) y la demanda en xeneral d'actividaes de promoción, paez indicativu d'una falta de correspondencia ente los deseos de los mirandinos y l'actuación institucional ${ }^{61}$.

A estos efectos, siete de cada diez mirandinos (70\%) conocen dalgún ciclu o dalguna campaña de promoción o protección del bron. El desconocimientu paez tar vinculáu a la edá, ya que son los menores de 35 años nos que rexistro'l total de rempuestes negatives, únicamente'1 10\% de los mozos conocía dalguna campaña o iniciativa, mientres que l'otru $90 \%$ nun conocía nada. Nel casu de los dos grupos d'edá restantes, el conocimientu de campañes, ciclos o iniciatives ${ }^{62}$ ye del $100 \%$.

N'últimu llugar, más de la metá de los mirandinos (56,7\%) consideren que'l bron foi, ye, y va siguir siendo un elementu identitariu de Miranda y una parte imborrable de la so historia. A ello hai que sumar qu'otra parte considerable (30\%) creen que, magar que seya como un elementu anecdóticu o una nota a pie de páxina, va siguir formando parte de la cultura de la zona. Poro, la tendencia xeneral ye optimista nos informantes más mayores, pero va tornándose más negativa según disminúi la edá de los encuestaos. Asina, paez que, demientres los mayores siguen considerándo'l bron como daqué clave na cultura mirandina, los más nuevos tienden a relegalo al güecu de lo anecdótico o mesmamente a pensar que va acabar escaeciéndose (ver Fig.22)

Únicamente unu de cada diez mirandinos $(10 \%)$ cree que van ser mui pocos los que guarden recuerdu o interés pola xerga, y una parte mínima $(3,30 \%)$ considera que va escaecese del too. Solo se rexistren estes rempuestes menos optimistes nel grupu de menores de 35 años (onde un 10\% defiende que se va escae-

61 Mui en relación cola situación sociollingüística n'Asturies, onde los asturianos demanden una mayor calidá de la política llingüística (Llera, 2017: 20).

62 Les rempuestes más recurrentes son los cursos impartíos por D. José Manuel Feito, asina como conferencies. 


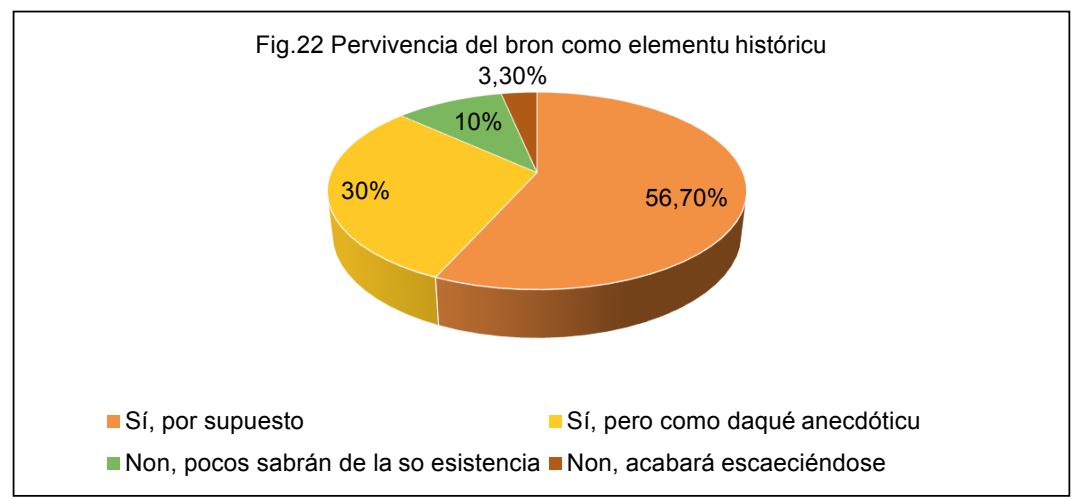

cer) y nel grupu de mediana edá (onde un $20 \%$ considera que son pocos los que van recordar que ye'l bron). Nos mayores de 65 años, la conciencia del bron como elementu cultural básicu y determinante de la historia de Miranda ye mui marcada (100\%).

De toes formes, la opinión mayoritaria ye claramente optimista y esperanzadora ya que ye una gran parte $(86,7 \%)$ la que considera que'l bron nun va caer nel olvidu, bien lo consideren dafechu o bien crean que va pervivir namás que como daqué anecdótico.

\section{Conclusiones}

Los criptolectos gremiales formen parte innegable de la bayura llingüística d'Asturies. De los ocho esistentes nel Principáu, el bron de Miranda pervive como constituyente básicu de la cultura mirandina. Lo que, nun entamu, paecía apuntar hacia una conservación nula no llingüístico, tórnase pervivencia según los resultaos obteníos.

Munchos de los elementos léxicos perviven non solo como recuerdu, sinón como ferramientes comunicatives con vigor na fala espontánea. Pero nun se fai estensivu a tola población: el nivel de conservación del bron ye directamente proporcional a la edá de los falantes. Mientres que los mayores y los adultos de mediana edá poseen na fala trazos léxicos del bron 
nun porcentax considerable, estos tán ausentes na fala de la mocedá. Del mesmu mou, hai una coincidencia ente la mayor conocencia y usus d'asturianu cola mayor conocencia y usu del bron.

Per otru llau, paez haber consensu social sobre la función de la xerga como ferramienta de comunicación. La conocencia de dalgunes voces en bron ta perfectamente constatada na población dende los 35 años, pero ye nula nos más nuevos. La cultura popular lleva a emparentar la xerga con llingües como l'asturianu. Hai palabres que tovía tienen bastante vitalidá, y que s'empleguen con frecuencia. Ye, por tanto, un exemplu de trespasu de términos de la fala secreta a la llingua común de la zona.

Nun paez qu'haya, actualmente, estigma llingüísticu, pero sí la mayor parte de la población almite que los caldereros yeren un grupu con mala consideración social pa colos que nun entendíen la xerga.

Finalmente, el bron sigue siendo una señá d'identidá de los mirandinos, que demanden una protección mayor de la xerga. Esto fai que podamos considerar el bron como una de les xergues que cuenten con un nivel d'activismu mayor n'Asturies.

\section{Referencies bibliográfiques}

Academia de la Llingua Asturiana (1996) Diccionariu de la Llingua Asturiana. Disponible en: <http://www.academiadelallingua.com/diccionariu/index.php $>$

Álvarez Balbuena, F. (2006) "Lengua" en Degaña. El secreto mejor guardado de Asturias. Degaña: Concejo de Degaña, 2006, pp.: 98-109.

Álvarez López, A. (2005) El Burón. La jerga de los vendedores y albarderos ambulantes de Forniella, Uviéu: Academia de la Llingua Asturiana.

Andrés, DíAz, R. (2008) “El eusquera y las jergas gremiales de Asturias" n'Euskera, LıII: 2. Disponible en: <www.euskaltzaindia.net/dok/euskera/72803.pdf>. [Consulta: 14/12/2017] 
(2013) “L'asturianu nes xergues gremiales d'Asturies", Archivum, LXIII, pp. 381-413.

Campandegui García, E. (2004) “El mansolea y los zapateros de Pimiango" en Sánchez Vicente X.X. (coord.), Xírigues. Lengua y vida de los artesanos asturianos ambulantes, Oviedo: Cajastur, pp.: 167-191.

Canella Secades, F. (1886) Estudios Asturianos (Cartafueyos d'Asturies), Oviedo.

Canellada, M. X. (1983) "En xíriga" en Philologica hispaniensia in honorem M. Alvar, vol. I, Madrid: Gredos.

Cuesta, G. (2016) “Identidad lingüística y fenómenos de transferencia en La Pola de Lena (Asturias)" Lletres asturianes, 115, pp.: 147-177.

Feito, J. M. (2002) Los Caldereros de Miranda. Historia, Antología y Vocabulario Bron-Castellano/Castellano-Bron. Avilés: Ediciones Azucel.

(1977) Artesanía popular asturiana, Gijón: Ayalga Ediciones.

(2004) "El bron y los caldereros de Miranda", en Sánchez Vicente, X.X. Xírigues. Lengua y vida de los artesanos asturianos ambulantes, Oviedo: Cajastur, pp.: 55-90.

(2005) Don Mariano Cubí i Soler, pedagogo, frenólogo, lingüista, primer recopilador de El Bron de los caldereros, Oviedo: Real Instituto de Estudios Asturianos.

(2014) Notas para la historia. Miranda de Avilés, Avilés: Nieva Ediciones.

García Arias, X. Ll. (2003) Gramática história de la lengua asturiana, Uviéu: Academia de la Llingua Asturiana.

(2004) “El cascón, la xíriga de los goxeros de Peñamellera" Lletres Asturianes, 85, pp.: 129-131.

García GonzÁLEZ, F. (1975) “El mansolea: una jerga gremial del Oriente de Asturias", Archivum, 25, pp.: 377-420.

Llano Roza de Ampudia, A. (1921) Dialectos jergales asturianos: Vocabularios de la xíriga y el bron. Uviéu/Oviedo.

Llera RAmo, F. J. (1994) Los asturianos y la lengua asturiana. Estudio sociolingüístico para Asturias, 1991, Uviéu: Serviciu de Publicaciones del Principáu d'Asturies. 
(2003) II Estudio sociolingüístico de Asturias, 2002, Uviéu: Academia de la Llingua Asturiana.

(2017) III Encuesta sociolingüística de Asturias. Avance de resultados, Uviéu: Academia de la Llingua Asturiana.

López Morales, H. (2004) Sociolingüística, Madrid: Gredos (Biblioteca Románica Hispánica, 70) (3. ㄹ Ed.)

Martín A., Fernández C., \& Conde F. (2004) “La xíriga o tamargu y los canteros del Oriente de Asturias" en Sánchez Vicente X.X. (coord.), Xírigues. Lengua y vida de los artesanos asturianos ambulantes, Oviedo: Cajastur, pp.: 99-138.

Pérez Melero, C. (2004) “El ergue y los canteros de la zona oriental”, en Sánchez Vicente X.X. (coord.), Xírigues. Lengua y vida de los artesanos asturianos ambulantes, Oviedo: Cajastur, 2004, pp.: 93-96.

Real Academia Española, Diccionario de la Lengua Española. Disponible en: $<$ http://dle.rae.es/?w=diccionario $>$.

Requena Santos, F. (1998). "Redes (sociales), análisis de", en Giner, S.; Lamo de Espinosa, E.; y Torres, C. (1998): Diccionario de Sociología, Madrid: Alianza.

(2002) "Redes sociales y Sociolingüística" en Sociolinguistic Studies, III: 1 . Disponible en: <https://www.researchgate.net/publication/240764614_Redes_sociales_y_sociolinguistica> [Consulta: 22/04/2018]

Rodrígues Gomes, J. (2008) Falas secretas. Estudo das gírias gremiais galego-portuguesas e ibéricas. Ourense: Associaçom Galega da Lingua.

Sánchez Vicente, X. X. (2004) Xírigues. Lengua y vida de los artesanos asturianos ambulantes, Oviedo: Cajastur.

Valdés DíAz, Á. (2008) El bron de San Juan de Villapañada, Grado: Ediciones La Cruz de Grado.

VVAA (2007) V Xornaes de llingües gremiales. Actes 2006, Avilés: Ediciones Nieva. 